\title{
Presence of microorganisms in children with pharyngotonsillitis and healthy controls: a prospective study in primary healthcare
}

\author{
Jon Pallon ${ }^{1,2,3} \cdot$ Martin Sundqvist $^{4} \cdot$ Mattias Rööst $^{1,2} \cdot$ Patrik Danielsson $^{5} \cdot$ Thomas Neumark $^{6} \cdot$ \\ Susann Skovbjerg ${ }^{7,8,9} \cdot$ Jonas Svedin $^{10} \cdot$ Katarina Hedin $^{1,11}$
}

Received: 9 December 2020 / Accepted: 23 February 2021 / Published online: 8 March 2021

(c) The Author(s) 2021

\begin{abstract}
Purpose Most studies on paediatric pharyngotonsillitis focus on group A streptococci. This study, however, analyses a broad spectrum of bacteria and viruses related to paediatric pharyngotonsillitis and evaluates their associated clinical symptoms and courses.

Methods This observational prospective study in primary healthcare includes 77 children aged $<15$ with a sore throat and 34 asymptomatic children, all of whom were sampled from the tonsils with an E-swab ${ }^{\circledR}$ for analysis with culture and PCR for 14 bacteria and 15 viruses. Patients were evaluated clinically, and their symptoms recorded in diaries for 10 days. Participants were followed up for 3 months by reviewing medical records.

Results A pathogen was detected in $86 \%$ of patients and in $71 \%$ of controls $(P=0.06)$. Bacteria were found in $69 \%$ of patients and $59 \%$ of controls $(P=0.3)$, and viruses in $36 \%$ and $26 \%$, respectively $(P=0.3)$. Group A streptococci was the most common finding, with a prevalence of $49 \%$ and $32 \%$, respectively $(P=0.1)$. Clinical signs were not useful for distinguishing pathogens. None of the controls and $16 \%$ of the patients reconsulted for a sore throat within 3 months.

Conclusion Bacteria were more common than viruses in both study groups. The high rate of pathogens in asymptomatic children interferes with diagnoses based on aetiology.
\end{abstract}

Keywords Pharyngotonsillitis $\cdot$ Aetiology $\cdot$ Children $\cdot$ Primary healthcare $\cdot$ PCR $\cdot$ Prospective

\section{Abbreviations \\ GAS Group A streptococci \\ PCR Polymerase chain reaction}

Jon Pallon

jon.pallon@med.lu.se

1 Department of Clinical Sciences in Malmö, Family Medicine, Lund University, Malmö, Sweden

2 Department of Research and Development, Region Kronoberg, Växjö, Sweden

3 Clinical Research Centre, Institutionskansliet För Kliniska Vetenskaper, Box 50332, 20213 Malmö, Sweden

4 Department of Laboratory Medicine, Clinical Microbiology, Faculty of Medicine and Health, Örebro University, Örebro, Sweden

5 Cityläkarna Primary Healthcare Centre, Region Kalmar County, Kalmar, Sweden

6 Region Kalmar County, Kalmar, Sweden

\section{Introduction}

Pharyngotonsillitis accounts for $6 \%$ of all primary healthcare visits by children [1] and leads to antibiotic prescriptions in 53-60\% of the cases [1-4]. The most important pathogen is the bacterium Streptococcus pyogenes (group

7 Department of Infectious Diseases, Institute of Biomedicine, Sahlgrenska Academy, University of Gothenburg, Gothenburg, Sweden

8 Department of Clinical Microbiology, Sahlgrenska University Hospital, Region Västra Götaland, Gothenburg, Sweden

9 Centre for Antibiotic Resistance Research (CARe), University of Gothenburg, Gothenburg, Sweden

10 Anderslöv Primary Healthcare Centre, Region Skåne, Anderslöv, Sweden

11 Futurum, Region Jönköping County, and Department of Health, Medicine and Caring Sciences, Linköping University, Linköping, Sweden 
A streptococcus; GAS), which can cause both severe nonsuppurative complications such as acute rheumatic fever and glomerulonephritis and immediate suppurative complications such as peritonsillar abscess, otitis media, and sinusitis. Non-suppurative complications are almost absent in high-income countries, and suppurative complications are too rare to justify antibiotic treatment. Current guidelines note that acute sore throat is a self-limiting infection that usually subsides within a week without antibiotic treatment, so the benefits of antibiotics must be weighed against adverse effects $[5,6]$.

Although GAS is the most common bacterial aetiology, it is only found in every third child with an acute sore throat and even less so in children younger than 5 years old [7]; that is, a majority of throat infections are caused by other pathogens, including respiratory viruses and other streptococcal species [8]. However, previous studies have often focused on a narrow spectrum of pathogens and relied on older methods such as culture and antigen detection $[9,10]$. Moreover, GAS is also found in $12 \%$ of asymptomatic children [7], which poses problems diagnosing test-positive patients.

A few studies of unselected children with an acute sore throat in primary healthcare have investigated a broad range of respiratory pathogens using both culture and molecular methods [6]. In addition, there is a knowledge gap regarding the presentation and clinical course associated with these pathogens as well as their carriage rate in healthy children.

This study has three aims: (1) to estimate the prevalence of 29 respiratory pathogens in children with an acute sore throat and in healthy controls; (2) to relate signs, symptoms, and clinical course to aetiology; and (3) to measure the incidence of complications and return visits for a sore throat within 3 months after clinical examination.

\section{Materials and methods}

\section{Design and setting}

In this prospective inception cohort study, we recruited children with an acute sore throat in primary healthcare and studied their symptoms and clinical course in relation to detected pathogens. For comparison, we also included noninfected controls. Both groups were followed for 3 months regarding recurrence and complications. Four primary healthcare centres in three counties in southern Sweden participated. Inclusion was open between 12 September 2014 and 17 October 2017.

\section{Participants}

Patients with suspected pharyngotonsillitis were initially identified by a triage nurse during a telephone assessment.
During office hours for ordinary ambulatory care, these patients and their parents were recruited to participate by the authors and other physicians. These patients were eligible if they were 0-14 years old and had a sore throat lasting less than 7 days as a major complaint (or signs of pharyngotonsillitis on clinical examination in the youngest). Exclusion criteria were imminent complications associated with a sore throat (peritonsillitis, sinusitis, acute otitis media, or lymphadenitis colli), symptoms of obstructive airway disease, and difficulties understanding Swedish. Apart from study-related procedures, all patients received care-as-usual, including any required tests or prescriptions.

The control group was recruited from asymptomatic children aged 0-14 who belonged to the same primary healthcare centre and sought care for non-infectious conditions.

We set out for a consecutive sampling of all eligible patients, but as the researchers were not always in the office and the triage nurses at times forgot about the study, we ended up using convenience sampling.

\section{Data collection}

After informed consent, the physician recorded background information on all participants. For patients, the physician also recorded signs and symptoms, working diagnosis, and decisions about antibiotics and ordered tests.

\section{Symptom diary}

We asked the parents to keep a structured diary for 10 days and record symptoms (e.g., sore throat, stuffed up or runny nose, pain when swallowing, cough, hoarseness, diarrhoea, vomiting, and resting more than half the day), analgesics use, antibiotics use, and morning temperature. We also asked them to assess daily if their child was still unwell and if their children missed preschool or school due to their illness. After completion, they returned the diary by mail in a prepaid envelope. Two weeks after inclusion, we called each patient as a reminder.

\section{Microbiological sampling}

Either the physician or trained staff at the primary healthcare centre collected a throat specimen from each participant by rolling a single nylon-flocked swab (E-Swab ${ }^{\circledR}$, Copan Diagnostics Inc., Murrieta, CA) repeatedly against both tonsils. The swab was transferred to liquid Amies medium in the accompanying container and stored in a refrigerator for overnight transport. All samples were analysed the following day at the Department of Clinical Microbiology, Sahlgrenska University Hospital, Gothenburg, Sweden. To ensure analysis was performed the day following collection, we limited inclusion to Monday 
through Thursday between 8 a.m. and 4 p.m. The laboratory staff were blinded to clinical data and any point-ofcare test results.

\section{Bacterial culture}

A calibrated loop (10 $\mu \mathrm{l})$ of diluted tonsillitis secretion was inoculated onto horse blood agar, Streptococcus agar, Haemophilus agar, and Arcanobacterium haemolyticum agar (all prepared in-house at Clinical Microbiology, Sahlgrenska University Hospital). The agar plates were incubated for 1 day at $34-36{ }^{\circ} \mathrm{C}$ in air with $5 \% \mathrm{CO}_{2}$, and after inspection incubated for another day at $34-36{ }^{\circ} \mathrm{C}$ in air, or for the Arcanobacterium agar, in air with $5 \% \mathrm{CO}_{2}$. Group A, B, C, and G streptococci, Streptococcus pneumoniae, Haemophilus influenzae, Moraxella catarrhalis, Staphylococcus aureus, and Gram-negative rods were enumerated and identified using standard bacteriological methods. A. haemolyticum was identified with a CAMP inhibition test.

\section{PCR detection of Fusobacterium necrophorum}

Bacterial DNA was extracted and purified from $500 \mu \mathrm{l}$ of diluted tonsillitis secretion using Amplicor Respiratory Specimen Preparation kits (Roche Diagnostics, Mannheim, Germany). F. necrophorum ssp. funduliforme was detected with a real-time PCR using previously published primers for the rpo gene (partial) [11], and SYBR green for detection of the amplified PCR product. The PCR conditions were as follows: initial denaturation at $95^{\circ} \mathrm{C}$ for $2 \mathrm{~min}$, followed by 40 cycles, each cycle consisting of $95^{\circ} \mathrm{C}$ for $15 \mathrm{~s}, 60^{\circ} \mathrm{C}$ for $15 \mathrm{~s}$, and $72{ }^{\circ} \mathrm{C}$ for $20 \mathrm{~s}$, all performed in a Rotor-Gene Q (Qiagen, Sollentuna, Sweden). After a pre-incubation step at $75^{\circ} \mathrm{C}$ for $90 \mathrm{~s}$, a melting curve analysis was performed from 75 to $95{ }^{\circ} \mathrm{C}$, rising by one degree each step, to confirm the correct $F$. necrophorum rpo gene amplification.

\section{PCR detection of viral and other bacterial pathogens}

Nucleic acids from $200 \mu \mathrm{l}$ of the tonsillitis secretion were extracted with a MagNA Pure LC instrument (Roche Diagnostics, Mannheim, Germany) using Total Nucleic Acid Isolation kits (Roche Diagnostic). Next, a multiplex real-time PCR was performed to detect 15 respiratory tract viruses (adenovirus, bocavirus, coronavirus 229E, OC43, NL63 and HKU-1, enterovirus, influenza A and B virus, metapneumovirus, parainfluenza virus $1-3$, rhinovirus and respiratory syncytial virus, RSV) and five bacteria (S. pneumoniae, $H$. influenzae, Bordetella pertussis, Chlamydophila pneumoniae, and Mycoplasma pneumoniae) [12].

\section{Follow-up}

Three months after inclusion, we reviewed the medical records of all patients and controls regarding return visits for a sore throat during the period and for a complication (peritonsillitis, sinusitis, acute otitis media, lymphadenitis colli, glomerulonephritis, or rheumatic fever) within 30 days of inclusion. We had access to relevant data from primary healthcare and hospitals at all study sites.

\section{Statistical analyses}

Based on earlier reports [7,9], we estimated that 100 patients and 100 controls would be sufficient to describe the epidemiologic situation and to reveal possible differences in aetiological prevalence between groups, primarily regarding GAS.

Data were analysed with SPSS 23.0 (IBM, Armonk, NY, USA). Continuous variables with non-normal distribution or with small sample sizes were reported as median (interquartile range, IQR). For comparison of three or more groups of variables not normally distributed, we used Kruskal-Wallis $H$ test, reported with the $H$ statistic, degrees of freedom and $P$ value. For comparison of categorical data, we used either Pearson $\chi^{2}$ or Fisher's exact test for independent groups, and McNemar's test for paired data.

Before analysis, the participants were grouped by age: $<1$ year (before preschool), 1-5 years (preschool), and 6-14 years (school). The microorganisms were also grouped, partly because of small numbers and partly to reflect clinical usefulness: "GAS" (corresponding to a positive culture or a rapid antigen detection test), "any bacteria" (positive in culture and/or PCR), "only viruses" (no benefit from antibiotics), and "no detected pathogen". We chose to use Centor score (one point each for fever, absence of cough, tonsillar coating, and tender cervical lymph glands) [13] rather than McIsaac score (age-adjusted Centor score) [14] to describe the summarized clinical features, because Centor score mirrors Swedish guidelines [15] and the two scoring systems are similar in the age group 3-14 years.

Aetiological predictive value, introduced by Gunnarsson and Lanke [16], is a statistical method that accounts for asymptomatic carriage when interpreting an aetiological test. As microbial carriage is also seen in symptomatic people, a positive finding could mean either infection or carriage. To correctly assess the test outcome, the level of uncertainty must first be quantified. Positive and negative predictive values with $95 \%$ confidence intervals can be calculated with known data for the prevalence of the pathogen (in our case GAS) for both patients and healthy subjects as well as the sensitivity of the test. It is also necessary to estimate "theta"-i.e., the ratio of GAS carriage in healthy individuals and in patients with a sore throat caused by a 
virus. Based on Gunnarsson and Lanke, we assumed a 90\% sensitivity of throat culture to detect GAS and a theta of 0.9 .

\section{Results}

\section{Characteristics}

The study included 79 patients and 34 controls. Two patients were later excluded from analysis due to withdrawn consent or symptoms lasting more than 7 days. Patients and controls were included in parallel, and most patients (63 of $77,82 \%$ ) and controls ( 28 of $34,82 \%$ ) were recruited during cold months (October-April). The age distribution was similar in both groups, with a median value of 7.8 years in patients (IQR 4.6-11) and 7.7 years in controls (IQR 4.2-10). Among the patients, 71 of 77 (92\%) were aged 3 or older. The median number of days with symptoms before consultation was 3 (IQR 2-5). Other background characteristics of the study population are presented in Table 1.

\section{Detected pathogens}

\section{Prevalence}

In 66 of 77 patients (86\%) and 24 of 34 controls (71\%), we detected at least one of the 29 targeted pathogens $(P=0.06)$. Bacteria were found in $69 \%$ of the patients and $59 \%$ of the controls $(P=0.3)$, and viruses in $36 \%$ and $26 \%$, respectively $(P=0.3)$. That is, bacteria were more common than viruses among both patients $(P=0.001)$ and controls $(P=0.02)$. Thirteen of the pathogens were never detected in the patients, and 17 were never detected in the controls.

GAS was the most prevalent pathogen in patients, making up a majority of bacterial findings, followed by $H$. influen$z a e, S$. aureus, influenza B virus, and rhinovirus. In controls,
GAS was also the most prevalent pathogen, followed by rhinovirus (Tables 2 and 3). We detected two or three concomitant pathogens in 23 patients (30\%), 15 of which were a combination of bacteria and viruses. The most common combination was GAS and influenza B virus $(n=4)$. Nine (26\%) of the controls had two or three concomitant pathogens. GAS was mostly detected as a sole pathogen (in $71 \%$ of patients and $55 \%$ of controls with GAS, respectively).

\section{Aetiology and age}

No pathogen was detected in the two patients who were under 1 year old. In the two older age groups, the distribution of pathogens in each group mirrored the overall pattern, and we found no differences between patients and controls that were statically significant (i.e., $P<0.05$ ). The relationship between age group and microbial findings is presented in Table 3.

\section{Aetiological predictive value for group A streptococci}

With a prevalence of $49 \%$ for patients and $32 \%$ for controls, the positive aetiological predictive value for GAS was 54\% (95\% CI 0-92\%). Restricting the calculation to patients with a Centor score of 3-4, the corresponding value was $67 \%$ (95\% CI 0-97\%).

\section{Clinical symptoms and management}

\section{Symptoms and aetiology}

The median number of days with a sore throat before consultation was similar between the mutually exclusive groups "any bacteria", "only viruses", and "no pathogen" $(H=2.5,2$ d.f., $P=0.3$ ) (Table 4). Swollen tonsils were found in $47 \%$ of patients with GAS and $31 \%$ of patients
Table 1 Characteristics of the study population

\begin{tabular}{llll}
\hline & \multicolumn{2}{l}{ Number $(\%)$} & \\
\cline { 2 - 4 } & Patients $(n=77)$ & Controls $(n=34)$ & $\begin{array}{l}\chi^{2} \text { (Fisher) } \\
P \text { value }\end{array}$ \\
\hline Age 0 & & & 1 (Fisher) \\
Age 1-5 & $2(3)$ & 0 & 0.8 \\
Age 6-14 & $27(35)$ & $11(32)$ & 0.8 \\
Female & $48(62)$ & $23(68)$ & 0.04 \\
Smoker in household & $52(68)$ & $16(47)$ & 1 \\
A history of recurring sore throat & $11(14)$ & $5(15)$ & 0.008 \\
Previous tonsillectomy & $25(32)$ & $3(9)$ & 1 (Fisher) \\
Antibiotic treatment in the last month & $5(6)$ & $2(6)$ & 0.03 (Fisher) \\
Prone to infections (parents' view) & $10(13)$ & 0 & 0.02 \\
Sore throat in family member in the last month & $49(64)$ & $1(3)$ & 0.01 \\
\hline
\end{tabular}


Table 2 Bacteria and viruses detected by culture or PCR in children with a sore throat and in controls

\begin{tabular}{|c|c|c|c|}
\hline & \multicolumn{3}{|c|}{ Number of patients (\%) } \\
\hline & Patients $(n=77)$ & Controls $(n=34)$ & Fisher or $\chi^{2}$ \\
\hline & & & $P$ \\
\hline \multicolumn{4}{|l|}{ Bacteria } \\
\hline Group A streptococci & $38(49)$ & $11(32)$ & $0.1^{\mathrm{e}}$ \\
\hline Group C streptococci & $1(1)$ & $3(9)$ & 0.08 \\
\hline Group G streptococci & - & $1(3)$ & 0.3 \\
\hline Haemophilus influenzae & $9(12)^{a}$ & $2(6)^{\mathrm{a}}$ & 0.5 \\
\hline Fusobacterium necrophorum & $1(1)$ & $1(3)$ & 0.5 \\
\hline Mycoplasma pneumoniae & - & $1(3)$ & 0.3 \\
\hline Staphylococcus aureus & $7(9)$ & $3(9)$ & 1 \\
\hline Gram-negative rods & $5(6)^{b}$ & $3(9)^{\mathrm{c}}$ & 0.7 \\
\hline Any bacteria & $53(69)$ & $20(59)$ & $0.3^{\mathrm{e}}$ \\
\hline \multicolumn{4}{|l|}{ Viruses } \\
\hline Adenovirus & $4(5)$ & - & 0.3 \\
\hline Bocavirus & - & $2(6)$ & 0.1 \\
\hline Coronavirus NL63 & $1(1)$ & $1(3)$ & 0.5 \\
\hline Coronavirus OC43 & $1(1)$ & - & 1 \\
\hline Enterovirus & $4(5)^{d}$ & $1(3)$ & 1 \\
\hline Influenza A virus & $2(3)$ & - & 1 \\
\hline Influenza B virus & $6(8)$ & - & 0.2 \\
\hline Metapneumovirus & $3(4)$ & - & 0.6 \\
\hline Parainfluenzavirus 1 & $1(1)$ & - & 1 \\
\hline Rhinovirus & $7(9)$ & $7(21)$ & $0.1^{\mathrm{e}}$ \\
\hline Respiratory syncytial virus & $2(3)$ & - & 1 \\
\hline Any virus & $28(36)$ & $9(26)$ & $0.3^{\mathrm{e}}$ \\
\hline
\end{tabular}

The following bacteria and viruses were not detected: Arcanobacterium haemolyticum, Bordetella pertussis, Chlamydophila pneumoniae, group B streptococci, Moraxella catarrhalis, Streptococcus pneumoniae, Coronavirus 229E and HKU-1, Parainfluenzavirus 2 and 3

${ }^{a}$ Haemophilus influenzae was detected in patients both as the sole finding $(n=2)$, and concomitant with group A streptococci $(n=2), S$. aureus $(n=3)$, and viruses $(n=3)$. Among controls, it was detected together with a virus $(n=1)$ and M. pneumoniae $(n=1)$

${ }^{\mathrm{b}}$ Enterobacter cloacae $(n=1)$, Klebsiella pneumoniae $(n=4)$

${ }^{\mathrm{c}}$ Pseudomonas spp. $(n=3)$

${ }^{\mathrm{d}}$ In one patient, the analysis could not differentiate between enterovirus and rhinovirus

${ }^{\mathrm{e}} \chi^{2}$ test was used

with only viruses $(P=0.3)$, and had a positive predictive value of $67 \%$ for GAS (95\% CI 51-80\%). Tender cervical lymph glands were common both in patients with GAS and in patients with "no pathogen" and had a positive predictive value of $53 \%$ for GAS (95\% CI 41-64\%). Coryza was more common in patients with only viruses than in patients with GAS $(P=0.04)$, but it had a low positive predictive value for viruses (24\%; 95\% CI 16-35\%). A cough was present in $46 \%$ of patients with only viruses and $24 \%$ of those with GAS $(P=0.2)$. A lack of a cough had a positive predictive value for GAS of 55\% (95\% CI 47-62\%).

\section{Centor scores}

In total, 47 of 77 patients (61\%) had a Centor score of $0-2$, and 30 patients (39\%) had a score of 3 (Table 4). As there were few patients with fever at consultation $(n=9)$, no patient had a score of 4 . A Centor score of 3 was seen in $45 \%$ of patients with GAS and in $31 \%$ of patients with only viruses $(P=0.5)$. The positive predictive value of a Centor score of 3-4 for GAS was 57\% (95\% CI 43-70\%) and the negative predictive value was 55\% (95\% CI 46-64\%). 
Table 3 Aetiology vs. age in children $<15$ years with a sore throat

\begin{tabular}{|c|c|c|c|c|c|c|c|c|c|}
\hline & \multicolumn{9}{|c|}{ Aetiology, $n(\%)$} \\
\hline & \multicolumn{3}{|l|}{ All ages ${ }^{a}$} & \multicolumn{3}{|l|}{ Age 1-5 } & \multicolumn{3}{|c|}{ Age 6-14 } \\
\hline & $\begin{array}{l}\text { Patients } \\
(n=77)\end{array}$ & $\begin{array}{l}\text { Controls } \\
(n=34)\end{array}$ & $P$ value & $\begin{array}{l}\text { Patients } \\
(n=27)\end{array}$ & $\begin{array}{l}\text { Controls } \\
(n=11)\end{array}$ & $P$ value & $\begin{array}{l}\text { Patients } \\
(n=48)\end{array}$ & $\begin{array}{l}\text { Controls } \\
(n=23)\end{array}$ & $P$ value \\
\hline Any pathogen & $66(86)$ & $24(71)$ & 0.06 & $24(89)$ & $9(82)$ & $0.6^{\mathrm{b}}$ & $40(83)$ & $15(65)$ & 0.09 \\
\hline Any bacteria & $53(69)$ & $20(59)$ & 0.3 & $18(67)$ & $6(55)$ & $0.7^{\mathrm{b}}$ & $33(69)$ & $14(61)$ & 0.5 \\
\hline GAS & $38(49)$ & $11(32)$ & 0.1 & $13(48)$ & $2(18)$ & $0.1^{\mathrm{b}}$ & $25(52)$ & $9(39)$ & 0.3 \\
\hline Only viruses & $13(17)$ & $4(12)$ & 0.5 & $6(22)$ & $3(27)$ & $1^{\mathrm{b}}$ & $7(15)$ & $1(4)$ & $0.3^{\mathrm{b}}$ \\
\hline
\end{tabular}

$P$ values are for Pearson $\chi^{2}$ test

GAS group A streptococci

a"All ages" also includes the two patients aged $<1$ year

${ }^{\mathrm{b}}$ Fisher's exact test

Table 4 Clinical signs vs. pathogen findings in children $<15$ years with a sore throat, $n(\%)$

\begin{tabular}{|c|c|c|c|c|c|}
\hline & $\begin{array}{l}\text { All patients } \\
(n=77)\end{array}$ & Any bacteria $(n=53)$ & GAS $(n=38)$ & Only viruses $(n=13)$ & $\begin{array}{l}\text { No } \\
\text { pathogen } \\
(n=11)\end{array}$ \\
\hline $\begin{array}{l}\text { Days with a sore throat prior to } \\
\text { visit, median (IQR) }\end{array}$ & $3(2-5)$ & $3(2.3-4.8)$ & $3(2-4.5)$ & $3(2-5.5)$ & $2(1-4)$ \\
\hline Cough & $24(31)$ & $16(30)$ & $9(24)$ & $6(46)$ & $2(18)$ \\
\hline Coryza & $33(43)$ & $20(38)$ & $11(29)$ & $8(62)$ & $5(45)$ \\
\hline Tender cervical lymph glands & $35(45)$ & $24(45)$ & $19(50)$ & $4(31)$ & $7(64)$ \\
\hline Tonsillar coating & $19(25)$ & $13(25)$ & $9(24)$ & $3(23)$ & $3(27)$ \\
\hline Tonsillar erythema & $54(70)$ & $38(72)$ & $29(76)$ & $8(62)$ & $8(73)$ \\
\hline Swollen tonsils & $27(35)$ & $21(40)$ & $18(47)$ & $4(31)$ & $2(18)$ \\
\hline Petechiae & $5(6)$ & $4(8)$ & $3(8)$ & $1(8)$ & - \\
\hline Raspberry tongue & $1(1)$ & $1(2)$ & $1(3)$ & - & - \\
\hline Scarlatine rash & $1(1)$ & $1(2)$ & $1(3)$ & - & - \\
\hline Impetigo & - & - & - & - & - \\
\hline Temperature $\geq 38.5^{\circ} \mathrm{C}$ & $7(9)$ & $3(6)$ & $3(8)$ & $3(23)$ & $1(9)$ \\
\hline \multicolumn{6}{|l|}{ Centor score } \\
\hline 0 & $6(8)$ & $3(6)$ & $2(5)$ & $3(23)$ & - \\
\hline 1 & $19(25)$ & $14(26)$ & $6(16)$ & $2(15)$ & $3(27)$ \\
\hline 2 & $22(29)$ & $16(30)$ & $13(34)$ & $2(15)$ & $2(18)$ \\
\hline 3 & $30(39)$ & $20(38)$ & $17(45)$ & $4(31)$ & $6(55)$ \\
\hline 4 & - & - & - & - & - \\
\hline
\end{tabular}

GAS group A streptococci

\section{Clinical course}

\section{Symptom diaries}

We received complete diaries from 55 of 77 patients $(71 \%)$. The response rate differed slightly between the groups: $74 \%$ for "any bacteria", $77 \%$ for "only viruses", and $55 \%$ for "no pathogen" ( $P=0.4$, Fisher). Most of these patients (52 of
55) reported a resolution of their sore throat within 10 days, although five experienced recurrent symptoms.

The median duration of a sore throat after consultation differed between groups, with the fastest resolution in GAS patients treated with antibiotics (median 3 days; IQR 1.5-3.5) and the slowest resolution in GAS patients not treated with antibiotics (median 4.5 days; IQR 2.3-8.8). The difference, however, was not statistically significant $(H=6.2,3$ d.f., $P=0.1)$. The gradual resolution of a sore throat is illustrated in Fig. 1. 
Fig. 1 Duration of a sore throat after a visit to a physician, as reported in symptom diaries of 55 children aged $0-14$. GAS group A streptococci, with and without antibiotic treatment

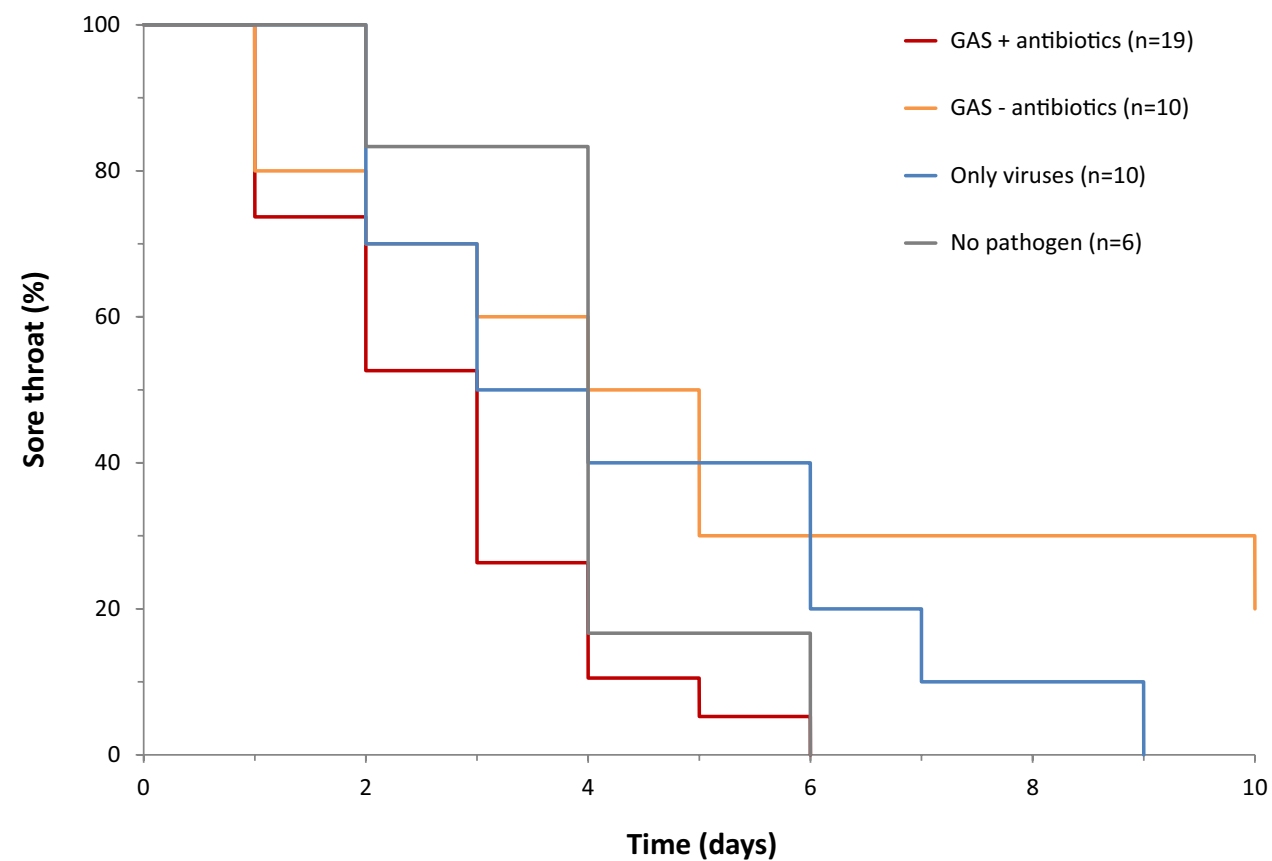

Self-reported prevalence of a sore throat, fever, and absence from preschool or school at days 3 and 7 in the different groups are presented in Supplementary Table 1.

\section{Three-month follow-up}

All 77 patients and 34 controls were followed up after 3 months. Twelve patients (16\%) had made return visits for a sore throat after a median of 25 days (IQR 18-53). None of the patients and controls had a complication and none were hospitalized.

Four of the twelve patients reported worsened or nonresolving symptoms, and they all had non-treated GAS at inclusion. The other eight patients reported a new episode, and five of these had GAS at inclusion, three of whom received antibiotics. None of the controls consulted for a sore throat during the follow-up.

\section{Discussion}

In this prospective observational study on pharyngotonsillitis in children presenting to primary healthcare, we found a high prevalence of bacteria and viruses in both patients $(86 \%)$ and controls $(71 \%)$. Bacteria were more common than viruses in both groups, and GAS was the most common pathogen. The observed differences in signs and symptoms between bacteria and viruses were not specific enough to be clinically useful. The fastest resolution of symptoms was seen in GAS patients treated with antibiotics. After 3 months, $16 \%$ of the patients had made return visits for a sore throat, but without a clear association to detected pathogens.

\section{Strengths and weaknesses}

To our knowledge, this is the first study on self-referred and unselected children with pharyngotonsillitis in primary healthcare that takes advantage of PCR to screen for a broad range of pathogens in both patients and controls and associates those findings with clinical symptoms and the course of the infection. Despite the lack of specific demographic data, we believe that this multicentre study is representative of children presenting to primary care with an acute sore throat. The data were collected in both urban and rural areas over three seasons, and the findings are reported by age strata to further increase their usefulness. Whether our findings can be replicated elsewhere depends on the epidemiological situation in those locations.

The low number of participants, especially controls, was less than we aimed for, and this could have introduced type II errors. Based on previous data, we expected to recruit a sufficient number of participants in one season, but failed to do so, mainly because the clinics were unable to provide enough resources. We also learned that children visiting for non-infectious causes are scarce, and they may not want to participate in a study while suffering from a sprained ankle or upset stomach. Aware of this limitation, we urge the reader to consider this an exploratory study.

Some methodological limitations need to be discussed. First, as we did not ask about fever previous to the visit, we might have missed important information, especially since 
the proportion of children with fever at the clinic was lower than expected (possibly explained by uncalibrated thermometers, use of antipyretics, or many visits in the morning). Second, although a throat swab may be more convenient for children than a nasopharyngeal swab and better reflect the pathogens of a pharyngeal infection, this technique could be an inferior way to detect viruses and result in false negatives [17]. Regardless of technique, because aetiological tests only test for the specified microorganisms, we probably missed other pathogens. By adding biomarker tests, we might have been able to classify the infection as viral or bacterial [18]. Third, as many diaries were never returned, we should have used other ways to obtain the information and help the parents, for example, by offering web-based forms.

\section{Interpretation}

Group A streptococcus (GAS) was the most prevalent pathogen in both patients and controls, a finding in line with the previous reports [7]. However, the high carriage rate made us wonder if there had been an outbreak of GAS during the study period; analysis of the temporal variations revealed no such fluctuations (data not shown). Normally, GAS in children under 5 years old is less prevalent than in older children, but our study could only confirm this in the controls, not in the patients. Group C or G streptococci were only found in one patient but in four of 34 controls, a finding congruent with a large observational study that suggests both an increasing incidence with age and a likely carriage state in children [19].

Haemophilus influenzae, S. aureus, and K. pneumoniae were found in a quarter of patients, as well as in controls. Although these bacteria can be associated with disease in children, they are more likely to represent a colonization [20]. M. catarrhalis, another common bacterium in the nasopharyngeal microbiome of children, was never detected [5].

The anaerobic bacterium Fusobacterium necrophorum has been suggested as a possible pathogen in adolescents with pharyngitis [21-23]. We detected $F$. necrophorum in only one patient, aged 14 and with a concomitant finding of influenza $B$ virus, and in one control, aged 3 . These findings are in line with a previous report of a $2 \%$ prevalence in children under 15 years old [23].

The prevalence of viruses in our study was much lower than the prevalence of viruses from a previous study using PCR [18]. This unexpected finding could be the result of the sampling errors described above, age distribution differences between our study and the previous studies, and epidemiologic differences between our settings and the previous study's settings. Among children, viruses become less prevalent with age [18], and two-thirds of our patients were 6-14 years old.
Rhinovirus was the most prevalent virus in both patients and controls, which is congruent with studies using PCR $[18,24]$, while adenovirus, the most prevalent virus in older studies [9, 10, 25], was less common. In our study, parainfluenzavirus, metapneumovirus, and RSV were only found in patients, which supports the findings of a study on young children with acute respiratory infection [24].

The high rate of bacteria and viruses in asymptomatic children makes it difficult to interpret a positive finding in patients, as there is good reason to assume that they have similar carriage rates [16]. This is especially true for GAS [7], rhinoviruses [24, 26], and adenoviruses [18]. The fact that most findings in our study were single pathogens does not contradict the idea of a simultaneous carriage and infection, as we had no test for aetiological causality and no estimate of false-negative findings. Both rapid antigen tests and the Centor criteria are used to detect GAS, not to distinguish between infection and colonization.

While detection of microorganisms is insufficient for determining causality, measuring the host response may get us closer. Repeated testing for streptococcal antibodies could retrospectively determine a likely infection with GAS [27], but this will not help the clinician at the time of visit. $\mathrm{C}$-reactive protein (CRP) and procalcitonin are biomarkers that have been suggested to distinguish bacterial from viral infections, but their usefulness lies in repeated measures in hospitalized patients, and have not been proven useful in diagnosing pharyngitis in adults [6]. Myxovirus resistance protein $\mathrm{A}(\mathrm{MxA})$ is a marker for viral infections, and a recent study found a clear association between elevated MxA levels and detection of viruses in children with febrile pharyngitis [18]. However, the differential diagnostic value for bacterial infection was poor, as an elevated MxA does not exclude a concomitant finding of GAS. Combining MxA with CRP could be a better approach, but this needs more evaluation [18]. Transcriptional profiling is another promising technique to differentiate viral detection from an active viral infection [26].

Rather than relying on biomarkers, the statistical method etiologic predictive value (EPV) considers asymptomatic carriage when interpreting an aetiological finding in patients [16]. Although this approach does not answer the question of causality, it does provide an important indication of the uncertainty. In our study, we found that the EPV of a GASpositive culture was only $54 \%$, no more than flipping a coin, and with an incredibly wide confidence interval due to the high carriage rate. Incidentally, a recent meta-analysis found that only $56 \%$ of children with GAS-positive had a serologically confirmed infection [28].

The large diagnostic uncertainty must also be weighed against the small clinical benefits of antibiotic treatment, the low risk of complications in untreated patients, and the adverse effects of antibiotics. Except for patients with severe 
symptoms, no prescription or a back-up prescription could therefore be a better approach, which is in line with current guidelines [5, 6].

Our study adds to previous knowledge $[9,18,29,30]$ by noting that the clinical presentation for viruses and bacteria was very similar. Viral features like cough and coryza were less common in patients with GAS, but as GAS was highly prevalent, the positive predictive values for viruses for these symptoms were still low. No single symptom was specific enough for GAS or viruses to change the post-test probability to $>85 \%$, a level of reasonable certainty that approaches the performance of a rapid antigen detection test [30]. Although pointing to difficulties in aetiological diagnosis in children with pharyngotonsillitis, we do not consider the results of this small descriptive study robust enough to change clinical guidelines.

\section{Conclusion}

With a high carriage rate of both viruses and bacteria among controls, it is likely that symptomatic patients also harbour these microorganisms alongside their active infection. Together with the low predictive values of signs and symptoms, this makes causal aetiological diagnosis in children with pharyngotonsillitis very challenging, even where rapid antigen detection tests are available. The development of a fast, specific, and cheap point-of-care marker for active infection would be of great value.

Supplementary Information The online version contains supplementary material available at https://doi.org/10.1007/s15010-021-01595-9.

Acknowledgements We would like to thank all participants and their parents for making this study possible. We would also like to thank all staff at the four primary healthcare centres for helping out with the study, as well as the laboratory staff at Sahlgrenska University Hospital. We are grateful for the valuable input from Professor Sigvard Mölstad on planning and conceiving the project plan, and for all his suggestions along the way.

Author contributions JP conceptualization, data curation, formal analysis, investigation, visualization, writing-original draft preparation, and writing-review and editing. MS conceptualization, formal analysis, and writing - review and editing. MR formal analysis, and writing-review and editing. PD conceptualization, investigation, and writing-review and editing. TN conceptualization, investigation, and writing-review and editing. SS investigation, writing — original draft preparation, and writing - review and editing. JS conceptualization, investigation, and writing - review and editing. $\mathrm{KH}$ conceptualization, formal analysis, funding acquisition, project administration, resources, supervision, and writing-review and editing.

Funding Open access funding provided by Lund University. This work was supported by the Swedish Public Health Agency, the Medical Research Council of Southeast Sweden and the Region Kronoberg, Sweden.
Availability of data and materials The datasets generated and analysed during the current study are not publicly available due to Swedish legislation (the Personal Data Act), but are available from the corresponding author on reasonable request.

\section{Declarations}

Conflict of interest The authors declare that they have no competing interests.

Ethics approval The study was approved by the regional ethics review board in Lund, Sweden: 2014/314, with one amendment: 2016/157.

Consent to participate Older children received verbal information about the study and, depending on reading ability, written information in a language adapted for children was provided. More detailed information was given to parents or legal guardians. The participants and their parents or legal guardians were given the opportunity to ask questions. Consent was obtained verbally from the child and in writing from parents or legal guardians. If only one parent or legal guardian was present, we asked that they inform the other person as soon as possible and contact us if he or she did not want to participate in the study. Participants could withdraw their consent at any time.

Open Access This article is licensed under a Creative Commons Attribution 4.0 International License, which permits use, sharing, adaptation, distribution and reproduction in any medium or format, as long as you give appropriate credit to the original author(s) and the source, provide a link to the Creative Commons licence, and indicate if changes were made. The images or other third party material in this article are included in the article's Creative Commons licence, unless indicated otherwise in a credit line to the material. If material is not included in the article's Creative Commons licence and your intended use is not permitted by statutory regulation or exceeds the permitted use, you will need to obtain permission directly from the copyright holder. To view a copy of this licence, visit http://creativecommons.org/licenses/by/4.0/.

\section{References}

1. Linder JA, Bates DW, Lee GM, Finkelstein JA. Antibiotic treatment of children with sore throat. JAMA. 2005;294:2315-22.

2. Pouwels KB, Dolk FCK, Smith DRM, Robotham JV, Smieszek T. Actual versus 'ideal' antibiotic prescribing for common conditions in English primary care. J Antimicrob Chemother. 2018;73:19-26.

3. Tyrstrup M, Beckman A, Molstad S, Engstrom S, Lannering C, Melander E, et al. Reduction in antibiotic prescribing for respiratory tract infections in Swedish primary care-a retrospective study of electronic patient records. BMC Infect Dis. 2016;16:709.

4. van den Broek DJ, Verheij TJ, Numans ME, van der Velden AW. Antibiotic use in Dutch primary care: relation between diagnosis, consultation and treatment. J Antimicrob Chemother. 2014;69:1701-7.

5. National Institute for Health and Care Excellence. Sore throat (acute): antimicrobial prescribing [Internet]. 2018. Available from: www.nice.org.uk/guidance/ng84. Accessed 12 Feb 2021.

6. Pelucchi C, Grigoryan L, Galeone C, Esposito S, Huovinen $\mathrm{P}$, Little $\mathrm{P}$, et al. Guideline for the management of acute sore throat. Clin Microbiol Infect. 2012;18:1-28. 
7. Shaikh N, Leonard E, Martin JM. Prevalence of streptococcal pharyngitis and streptococcal carriage in children: a metaanalysis. Pediatrics. 2010;126:e557-64.

8. Bisno AL, Gerber MA, Gwaltney JM Jr, Kaplan EL, Schwartz RH, Infectious Diseases Society of A. Practice guidelines for the diagnosis and management of group A streptococcal pharyngitis. Clin Infect Dis. 2002;35:113-25.

9. Esposito S, Blasi F, Bosis S, Droghetti R, Faelli N, Lastrico A, et al. Aetiology of acute pharyngitis: the role of atypical bacteria. J Med Microbiol. 2004;53:645-51.

10. Putto A. Febrile exudative tonsillitis: viral or streptococcal? Pediatrics. 1987;80:6-12.

11. Jensen A, Kristensen HL, Prag J. Detection of Fusobacterium necrophorum subsp. funduliforme in tonsillitis in young adults by real-time PCR. Clin Microbiol Infect. 2007;13:695-701.

12. Andersson ME, Olofsson S, Lindh M. Comparison of the FilmArray assay and in-house real-time PCR for detection of respiratory infection. Scand J Infect Dis. 2014;46:897-901.

13. Centor RM, Witherspoon JM, Dalton HP, Brody CE, Link K. The diagnosis of strep throat in adults in the emergency room. Med Decis Mak. 1981;1:239-46.

14. McIsaac WJ, Goel V, To T, Low DE. The validity of a sore throat score in family practice. CMAJ. 2000;163:811-5.

15. Läkemedelsverket [Swedish Medical Products Agency]. Handläggning av faryngotonsillit $\mathrm{i}$ öppenvård—ny rekommendation [Management of pharyngotonsillitis in ambulatory care-new recommendation]. Inf Läkemedelsverket. 2012;23:18-25.

16. Gunnarsson RK, Lanke J. The predictive value of microbiologic diagnostic tests if asymptomatic carriers are present. Stat Med. 2002;21:1773-85.

17. Robinson JL, Lee BE, Kothapalli S, Craig WR, Fox JD. Use of throat swab or saliva specimens for detection of respiratory viruses in children. Clin Infect Dis. 2008;46:e61-4.

18. Ivaska L, Niemela J, Lempainen J, Osterback R, Waris M, Vuorinen T, et al. Aetiology of febrile pharyngitis in children: potential of myxovirus resistance protein $\mathrm{A}(\mathrm{MxA})$ as a biomarker of viral infection. J Infect. 2017;74(4):385-92.

19. Frost HM, Fritsche TR, Hall MC. Beta-hemolytic nongroup A streptococcal pharyngitis in children. J Pediatr. 2019;206:268-73.
20. Kumpitsch C, Koskinen K, Schopf V, Moissl-Eichinger C. The microbiome of the upper respiratory tract in health and disease. BMC Biol. 2019;17:87.

21. Centor RM, Atkinson TP, Ratliff AE, Xiao L, Crabb DM, Estrada CA, et al. The clinical presentation of Fusobacterium-positive and streptococcal-positive pharyngitis in a university health clinic: a cross-sectional study. Ann Intern Med. 2015;162:241-7.

22. Hedin K, Bieber L, Lindh M, Sundqvist M. The aetiology of pharyngotonsillitis in adolescents and adults-Fusobacterium necrophorum is commonly found. Clin Microbiol Infect. 2015;21:263 e1-267.

23. Van TT, Cox LM, Cox ME, Dien BJ. Prevalence of Fusobacterium necrophorum in children presenting with pharyngitis. J Clin Microbiol. 2017;55:1147-53.

24. Rhedin S, Lindstrand A, Rotzen-Ostlund M, Tolfvenstam T, Ohrmalm L, Rinder MR, et al. Clinical utility of PCR for common viruses in acute respiratory illness. Pediatrics. 2014;133:e538-45.

25. Hsieh TH, Chen PY, Huang FL, Wang JD, Wang LC, Lin HK, et al. Are empiric antibiotics for acute exudative tonsillitis needed in children? J Microbiol Immunol Infect. 2011;44:328-32.

26. Heinonen S, Jartti T, Garcia C, Oliva S, Smitherman C, Anguiano $\mathrm{E}$, et al. Rhinovirus detection in symptomatic and asymptomatic children: value of host transcriptome analysis. Am J Respir Crit Care Med. 2016;193:772-82.

27. Johnson DR, Kurlan R, Leckman J, Kaplan EL. The human immune response to streptococcal extracellular antigens: clinical, diagnostic, and potential pathogenetic implications. Clin Infect Dis. 2010;50:481-90.

28. Oliver J, Malliya Wadu E, Pierse N, Moreland NJ, Williamson DA, Baker MG. Group A streptococcus pharyngitis and pharyngeal carriage: a meta-analysis. PLoS Negl Trop Dis. 2018;12:e0006335.

29. Le Marechal F, Martinot A, Duhamel A, Pruvost I, Dubos F. Streptococcal pharyngitis in children: a meta-analysis of clinical decision rules and their clinical variables. BMJ Open. 2013;3:e01482.

30. Shaikh N, Swaminathan N, Hooper EG. Accuracy and precision of the signs and symptoms of streptococcal pharyngitis in children: a systematic review. J Pediatr. 2012;160:487-93. 